\title{
SIMULTANEOUS DETERMINATION OF ATRAZINE AND SODIUM DICLOFENAC IN NATURAL WATER BY SPECTROPHOTOMETRIC APPROACHES
}

\author{
JUANITA FREER ${ }^{a, b^{*}}$, CAROLINA BAEZA ${ }^{c}$, DAVID CONTRERAS ${ }^{a, b}$, CESAR SOTO $^{a}$, STEPHANIE CORRALES \\ AND NATALY MORENO
}

\author{
${ }^{a}$ Faculty of Chemical Sciences, ${ }^{b}$ Biotechnology Center and, ${ }^{c}$ Faculty of Environmental Sciences and EULA-Chile Centre, \\ University of Concepción, P. O. Box 160,Concepción, Chile.
}

\begin{abstract}
Diclofenac (DCF) and Atrazine (ATZ) are pollutants, present in natural waters. To develop new technologies for the abatement of these compounds, it is necessary to develop fast and low cost methods for routine quantification. In this work, two fast and accurate methods for the simultaneous determination of DCF y ATZ in natural waters were developed. These methods are based in spectrophotometric second order derivative (SDS) and partial least-squares (PLS) multivariate calibration from UV-VIS spectroscopic data. Both methods were compared with chromatographic reference methods. Limit of detection (LOD), limit of quantification (LOQ) and recovery values obtained for river water sample were similar. In the case of DCF, the LOD ranged from $3 \times 10^{-8}(\mathrm{PLS})$ to $1 \times 10^{-7}$ (SDS), while for ATZ, LOD ranged from $1 \times 10^{-8}$ (PLS) to $3 \times 10^{-6}$ (GC-MS). For DCF, the LOQ ranged from $9 \times 10^{-8}$ (PLS) to $9 \times 10^{-7}$ (HPLC-UV), while for ATZ, LOQ ranged from $4 \times 10^{-8}$ (PLS) to $5 \times 10^{-6}$ (GC-MS). For DCF, the recovery (\%) ranges from 97 (SDS) to 106 (PLS), while for ATZ, recovery (\%) ranges from 91 (PLS) to 99 (SDS).
\end{abstract}

Keywords: Atrazine, diclofenac, simultaneous determination, derivative spectrophotometry, PLS

\section{INTRODUCTION}

Atrazine, 6-chloro-N2-ethyl-N4-(1-methylethyl)-1,3,5-triazine-2,4diamine (ATZ), and diclofenac, 2-((2,6-dichlorophenyl)amino)benzeneacetic acid (DCF), are chemicals that have been used extensively over the last decades. ATZ and DCF are trace organic contaminants found in surface and groundwater, and detected in drinking water after conventional treatment, in several countries

ATZ is a selective triazine herbicide used to control broadleaf and grassy weeds in corn, sorghum, sugarcane, pineapple, christmas trees, and other crops, and in conifer reforestation plantings. It is also used as a nonselective herbicide on non-cropped industrial lands and on fallow lands. ATZ has been banned by the European Union [1]. Even though, the toxicity associated with ATZ has been documented extensively [2], ATZ continues to be used in the US, and in many other countries, like Chile. ATZ has been classified as a Restricted Use Pesticide (RUP) due to its potential for groundwater contamination [3].

DCF is an important non-steroidal anti-inflammatory drug widely used for human and animals to reduce inflammation and pain. It is primarily available as the sodium salt. DCF is eliminated through metabolism and subsequent urinary and biliary excretion. DCF has been found in many surface waters and even groundwater aquifers. The fate of DCF has been described in different compartments of the environment and photo-degradation and bio-degradation have been identified as major sinks for the parent substance $[4,5]$. DCF is one of the most important pharmaceutically active compounds detected in the aquatic environment [6].

Different analytical techniques have been reported for ATZ in water, by using chromatographic techniques. The limit of detection (LOD) in a number of monitoring surveys ranged between 0.02 and $1 \mu \mathrm{g} \mathrm{L}^{-1}$. Yokley and Cheung [7] used gas chromatography /mass selective detection (GC/MSD) in the selected ion monitoring (SIM) mode in water samples buffered at $\mathrm{pH} 10$ and partitioned in ethyl acetate, having LOD of $0.05 \mu \mathrm{g} \mathrm{L}^{-1}$ and limit of quantification (LOQ) of $0.10 \mu \mathrm{g} \mathrm{L} \mathrm{L}^{-1}$. ATZ determined by gas chromatography /mass spectrometry (GC/MS) with solid phase extraction (SPE) in raw water and drinking-water LOD was $10 \mathrm{ng} \mathrm{L}^{-1}$ [8]. LOD's for triazines determined by capillary GC with nitrogen thermionic specific detection and HPLC with photodiode array absorption detection following extraction with styrene-divinylbenzene sorbents and elution with acetone were lower than $5 \mathrm{ng} \mathrm{L}^{-1}$ [9]. ATZ is also determined by isotope dilution GC/MS with SPE, the method LOD in surface water is 1 $\mathrm{ng} \mathrm{L^{-1 }}[10]$. In the case of a large volume injection approach using $50 \mu \mathrm{L}$ of the 40 -fold concentrated extract, the LOD in river water is $2 \mathrm{ng} \mathrm{L}^{-1}$ [11]. By high performance liquid chromatography/Mass Spectrometry (HPLC/MS) method utilizing online SPE [12] or ultra-HPLC combined with tandem-MS [13], the LOQ is $50 \mathrm{ng} \mathrm{L}^{-1}$ or $12 \mathrm{ng} \mathrm{L}^{-1}$, respectively. Other methods are included in the United States Environmental Protection Agency's (2009) document on
Analytical Methods Approved for Drinking Water Compliance Monitoring of Organic Contaminants: a) For the GC/MS method [14], the sample is extracted in a liquid-solid extractor, eluted with dichloromethane, and concentrated by evaporation before measurement by ion trap mass spectrometer (LOD $0.1 \mathrm{ng}$ $\mathrm{L}^{-1}$ ) or magnetic sector MS (LOD $0.3 \mathrm{ng} \mathrm{L}^{-1}$ ); b) For the nitrogen-phosphorus method [15], the sample is extracted with dichloromethane, dried, concentrated with methyl tertiary-butyl ether and measured by nitrogen-phosphorus detection (LOD $0.13 \mathrm{ng} \mathrm{L}^{-1}$ ); c) For the electron capture detection method [16], using hexane extraction.

Spectrophotometric methods have also been used for the determination of ATZ in contaminated water [17]. Amador-Hernández et al. [17] reported a LOD for ATZ equal to $0.11 \mu \mathrm{g} \mathrm{mL}^{-1}\left(5 \times 10^{-7} \mathrm{~mol} \mathrm{~L}^{-1}\right)$ and a LOQ equal to 0.35 $\mu \mathrm{g} \mathrm{mL}^{-1}\left(2 \times 10^{-6} \mathrm{~mol} \mathrm{~L}^{-1}\right)$ with a spectrophotometric method by PLS in ultrapure water combined with dicamba.

Innovative techniques with HPLC-UV have been recently developed. Zhou and Gao [18] developed a temperature-controlled ionic liquid-phase microextraction in combination with HPLC-UV reaching a LOD of atrazine equal to $0.06 \mu \mathrm{g} \mathrm{L}^{-1}\left(3 \times 10^{-10} \mathrm{~mol} \mathrm{~L}^{-1}\right)$ in a mixture with two other triazine herbicides (cyanazine and simazine). Qiao et al. [19] developed a method based in a dispersive solid-phase extraction with magnetic microspheres coupled with a HPLC-UV reaching a LOD of atrazine equal to $0.37 \mathrm{ng} \mathrm{mL}^{-1}\left(2 \times 10^{-9} \mathrm{~mol} \mathrm{~L}^{-1}\right)$ in a mixture with cyanazine.

Several analytical methods have been described in the literature for the quantitative determination of DCF, by UV-visible spectrophotometry, HPLC, capillary electrophoresis and MS [20,21]. DCF can be analyzed by GC/MS, if it is derivatized first, method frequently used in the past $[4,22]$. Some studies used HPLC to measure DCF [ $23-25]$. The sensitivity of GC/MS and HPLC is in the low or sub $\mu \mathrm{g} \mathrm{L}^{-1}$ range and only with a pre-concentration by the factor of $100-1000$ environmental concentrations of residual pharmaceutically active compounds (PhACs) can be measured [26]. The pre-concentration is generally achieved by SPE. In environmental samples the rather unselective SPE leads to the problem that also other micropollutants with comparable characteristics are preconcentrated and the target compound has to be selected out of a matrix of different organic molecules [26]. Technological advances in LC/MS make this method nowadays to be the more appropriate, with the advantage, that no derivatization is needed prior to measurement, compared to GC/MS. Tools like triplequadrupole MS, tandem (MS-MS) and different ionization methods allow higher selectivity and sensitivity $[27,28]$.

Given the intense use of ATZ and DCF, both compounds are ubiquitous within natural water matrixes, therefore in this study we have developed and evaluated analytical methods for a rapid simultaneous determination of ATZ and DC in water by UV-VIS multivariate calibration and by derivative spectrophotometry. These methods are compared with chromatographic methods as reference. 


\section{EXPERIMENTAL}

\subsection{Reagents}

All reagents were analytical reagent grade. Atrazine (ATZ, 99.8\%) and diclofenac sodium salt (DCF, $99.8 \%$ ) were purchased from Sigma Aldrich. Each stock solution was prepared by dissolving ATZ $(0.876 \mathrm{mg})$ or DCF $(1.27$ $\mathrm{mg}$ ) in $50 \mathrm{~mL}$ in nanopure water, resulting in a concentration equal to $8.0 \times 10^{-5}$ mol L ${ }^{-1}$. Stock solutions were stored at $4^{\circ} \mathrm{C}$ and protected from light. Other ranges of concentrations were prepared by appropriate dilution.

\subsection{Instruments}

A UV-Vis spectrophotometer model Lambda12 (Perkin Elmer, USA), with $10 \mathrm{~mm}$ quartz cells was used for recorded of the absorption and derivative absorption spectra. The spectra were recorded on the range of $190-390 \mathrm{~nm}$, with a scan rate of $480 \mathrm{~nm} \mathrm{~s}^{-1}$, slit of $0.5 \mathrm{~nm}$ and $0.5 \mathrm{~nm}$ of resolution. The first, second, third and fourth derivate were calculated by tested $9,13,19,25,37$ and 49 derivatization points. The spectra data were processed by the software UV-WinLab Version 5.0.

DCF and ATZ were quantified by reverse-phase HPLC, using a HPLC UVVIS Merck-Hitachi (Elite Lacrom) with a Hibar $150 \mathrm{~mm}-4.6 \mathrm{~mm}$ Purospher ${ }^{\circledR}$ STAR RP-18 endcapped $(5 \mu \mathrm{m})$ column with a flow of $1 \mathrm{~mL} \mathrm{~min}^{-1}$. The mobile phase was $70 \% \mathrm{v} / \mathrm{v}$ methanol and $30 \% \mathrm{v} / \mathrm{v} 20 \mathrm{mM}$ phosphate buffer ( $\mathrm{pH} 2.5$ ).

ATZ was quantified by GC-MS in a Hewlett-Packard HP 5890 Series II GC equipped with an HP5972 MSD detector. The analytical column used was an HP-5MS $(30 \mathrm{~m} \times 0.25 \mathrm{~mm} \times 0.25 \mu \mathrm{m})$ with $\mathrm{He}$ as gas carrier at a constant flow rate of $1 \mathrm{~mL} \mathrm{~min}^{-1}$. The oven temperature program was $100^{\circ} \mathrm{C} \times 1 \mathrm{~min}$; $30^{\circ} \mathrm{C} \times 1 \mathrm{~min}^{-1}, 130^{\circ} \mathrm{C} \times 1 \mathrm{~min} ; 8^{\circ} \mathrm{C} \times \min ^{-1}, 220^{\circ} \mathrm{C} \times 1 \mathrm{~min} ; 30^{\circ} \mathrm{C} \times \min ^{-1}, 280^{\circ} \mathrm{C}$ $\times 1 \mathrm{~min}$. The temperatures of the injector and interface were $250^{\circ} \mathrm{C}$ and $280^{\circ} \mathrm{C}$, respectively. The identification of the ATZ was performed by comparing the spectrum with a library mass spectra database (NIST/EPA/NIH7SK).

\subsection{Procedure for calibration graphs of ATZ and DCF in mixtures}

Solutions containing both analytes were prepared by mixing aliquots of stock solutions and diluted with nanopure water. The calibration procedure was carried out for: (a) ATZ ranged from $1.12 \times 10^{-7}$ to $1.00 \times 10^{-5} \mathrm{~mol} \mathrm{~L}^{-1}$, containing DCF at a constant concentration of $4.0 \times 10^{-6} \mathrm{~mol} \mathrm{~L}^{-1}$ and (b) DCF ranged from $4.03 \times 10^{-7}$ to $1.00 \times 10^{-5} \mathrm{~mol} \mathrm{~L}^{-1}$, containing ATZ at a constant concentration of $4.0 \times 10^{-6} \mathrm{~mol} \mathrm{~L}^{-1}$. In all cases, the corresponding absolute values of the second derivative spectra at $224.0 \mathrm{~nm}$ for ATZ and $231.6 \mathrm{~nm}$ for DCF were obtained and then these values were plotted against the corresponding concentrations.

2.4 Procedure for simultaneous determination of ATZ and DCF in natural water

A sample from Bio-Bio river, Chile (-360 50'49.62', -730 3' 18.19'”) was collected on January 2012. This sample was filtered $(0.45 \mu \mathrm{m}$, PVDF membrane) and kept at $4^{\circ} \mathrm{C}$ until analysis. The river water sample was spiked with different mixtures of DCF and ATZ ranging from $3.0 \times 10^{-6} \mathrm{~mol} \mathrm{~L}^{-1}$ to $8.0 \times 10^{-6} \mathrm{~mol} \mathrm{~L}^{-1}$ at molar ratios between 2:0.75 and 0.75:2 (DCF:ATZ). The ATZ and DCF were measured directly. For each solution, five repetitions were made. Then, the second derivative spectra were evaluated and the concentrations of each compound were calculated, allowing the determination of the corresponding values of recovery and relative standard deviation (RSD).

\subsection{Procedure for photo stability studies of $A T Z$ and $D C F$}

Individual aqueous solutions of DCF and ATZ containing $8.0 \times 10^{-6} \mathrm{~mol} \mathrm{~L}^{-1}$ were prepared and each solution used in photo-stability studies. The solutions were exposed to direct light, indirect light and kept in darkness, and the second derivative spectra were evaluated every $30 \mathrm{~min}$ for $5 \mathrm{~h}$ and then at $24 \mathrm{~h}$.

\subsection{Partial least squares (PLS) calibration method}

PLS models were performed by the software Pirouette Ver. 4.5 (Infometrixinc.). Seventy four independent standards were used for the calibration data set and twenty five for the external validation set, ranging over the same values as those described in section Procedure for calibration graphs of DCF and ATZ in mixtures. The recorded spectra data were preprocessing by mean-centering. The wavelength region between 190 and $390 \mathrm{~nm}(0.5 \mathrm{~nm}$ of resolution) was selected for multivariate calculation in order to minimize the influence of variables that do not contribute to the model but could contribute to the error component. The outlier diagnosis was carried out through the cross validation performed, considering the Studentized residual together with Leverage with thresholds based on a $95 \%$. The outlier samples were eliminated, and then the models were reconstructed, being optimized, validated and utilized for all the calculations.

\subsection{PLS Validation and Optimization.}

All the models utilized cross validation, removing in turn each standard from the training set and then predicting the excluded sample with the calibration. The prediction residual error sum of squares (PRESS), standard error of cross-validation (SEV) as well as the correlation coefficient (rVal) for the predicted $Y$ values versus known $Y$ values were calculated, considering the cross validation [29].

These parameters were calculated according to Ragno et al. [30] and Afkhami et al. [31].

$$
\operatorname{PRESS}=\mathbf{f}^{\mathrm{T}_{\mathbf{f}}}
$$

Where $\mathbf{f}$ is the prediction residual matrix.

\subsection{Detection limit for multivariated methods.}

LOD for multivariate calibrations were determined according to Soto et al. $[32,33]$. Creating a surrogate signal variable (SSV) $[34,35]$ in order to create a pseudo-univariated model. The selected SSVs were the model predicted values. Thus, the LOD was calculated in a manner similar to that used for SDS.

\section{RESULTS AND DISCUSSION}

\subsection{Solvents election and spectral behavior}

Due to the difference in the structure of the two compounds (Figure 1) it is possible to expect different spectral behavior depending on the solvent. In order to see the solvent effect the spectra were recorded in ethanol, methanol, acetonitrile and water. Water-spectra showed higher and defined spectral bands.

Due that the classical spectra of both compounds overlap (Figure 2), the simultaneous determination of ATZ and DCF requires: a) the use of separation techniques before their detection, or b) the application of a chemometric technique for the resolution of the binary system. The problem was solved by using a) derivative spectroscopy and b) partial least square calibration (PLS).<smiles>O=C(Cc1ccccc1Nc1c(Cl)cccc1Cl)O[Na]</smiles><smiles>[Z17][Z17]([H])([H])Nc1nc(Cl)nc(NCC)n1</smiles>

Figure 1. Molecular structure for (a) DCF and (b) ATZ.

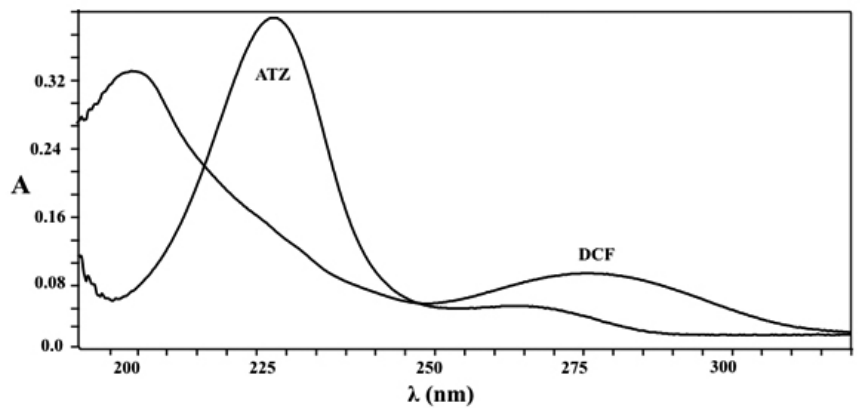

Figure 2. Zero-order spectra in water of DCF and ATZ $\left(4.0 \times 10^{-5} \mathrm{~mol}\right.$ $\mathrm{L}^{-1}$ each)

\subsection{Derivative Spectrophotometric Method.}

The digital derivative spectrophotometric method used is based on a mathematic computational model proposed by Savitzky and Golay [36], where the spectral resolution is sacrificed in order to increase strongly the signal/ noise ratio, favoring the accuracy of the results and the precision of the method. Different derivative (from first to fourth) spectra were obtained (testing 9, 13, $19,25,37,49$ derivatization points). The first derivative spectrum did not show regions allowing the simultaneous determination of both compounds. In the third and fourth derivatives spectra sensitivity is low. The second derivative spectrum allowed the simultaneous determination of DCF and ATZ by zero crossing at 224.0 and $231.6 \mathrm{~nm}$, respectively (Figure 3 ) with an amplification 
factor of 1000 and 37 derivative points. In Figure 3 is showed the second derivative spectra for DCF (keeping concentration of ATZ constant at $4.0 \times 10^{-6}$ $\mathrm{mol} \mathrm{L}^{-1}$ ) and ATZ (keeping concentration of DCF constant at $4.0 \times 10^{-6} \mathrm{~mol} \mathrm{~L}^{-1}$ ) at concentrations of $(4,6,8$, and 10$) \times 10^{-6} \mathrm{~mol} \mathrm{~L}^{-1}$.

The calibration graphs were establishing by measuring at appropriated wavelengths in the second derivative spectra. The analytical parameters are shown in Table 1. These analytical features were obtained used the criteria given by ICH Harmonized Tripartite Guideline [37], to calculate LOD and LOQ. The following equations were used: $3.3 \sigma / \mathrm{S}$ and $10 \sigma / \mathrm{S}$, respectively, where $\mathrm{S}$ is the slope of the calibration curve and $\sigma$ is the standard deviation corresponding to the response of 11 blanks. The repeatability, expressed as relative standard deviation (RSD), was obtained by using 10 standard samples containing $3.0 \times 10^{-6}, 8.0 \times 10^{-6}$ and $9.0 \times 10^{-6} \mathrm{~mol} \mathrm{~L}^{-1}$ of each analyte and 3 replicates of each concentration. The determination range was defined between the LOQ and the loss of linearity. In this context, it is possible to obtain an acceptable linear range (linear ranges, in $\mathrm{mol} \mathrm{L}^{-1}$, are shown in first row Table 1) with accuracy and precision in the results when the proposed method is applied.

Table 1.Analytical features.

\begin{tabular}{|c|c|c|c|c|c|c|c|}
\hline \multirow{2}{*}{ Parameter } & \multicolumn{2}{|c|}{ SDS } & \multicolumn{2}{|c|}{ PLS } & \multicolumn{2}{|c|}{ HPLC-UV } & \multirow{2}{*}{$\begin{array}{c}\text { GC-MS } \\
\text { ATZ }\end{array}$} \\
\hline & DCF & ATZ & DCF & ATZ & DCF & ATZ & \\
\hline $\begin{array}{l}\text { Liner Range } \\
\left(\mathrm{mol} \mathrm{L}^{-1}\right)\end{array}$ & $\begin{array}{c}4.03 \times 10^{-7}- \\
1.00 \times 10^{-5}\end{array}$ & $\begin{array}{c}1.12 \times 10^{-7}- \\
1.00 \times 10^{-5}\end{array}$ & $\begin{array}{c}8.87 \times 10^{-8}- \\
1.00 \times 10^{-5}\end{array}$ & $\begin{array}{c}3.58 \times 10^{-8}- \\
1.00 \times 10^{-5}\end{array}$ & $\begin{array}{l}8.6 \times 10^{-7}- \\
2.50 \times 10^{-5}\end{array}$ & $\begin{array}{l}2.0 \times 10^{-6}- \\
2.50 \times 10^{-5}\end{array}$ & $\begin{array}{l}4.63 \times 10^{-6}- \\
3.71 \times 10^{-5}\end{array}$ \\
\hline $\begin{array}{l}\text { Repeatability } \\
\text { (RSD \%) }\end{array}$ & 5 & 3 & 3 & 5 & 1 & 1 & 7 \\
\hline $\begin{array}{l}\text { Linear regression } \\
\qquad\left(C, \mathrm{~mol} \mathrm{~L}^{-1}\right)\end{array}$ & $\begin{array}{c}\mathrm{DU}_{1}=5.18 \times \\
10^{4} C-0.009\end{array}$ & $\begin{array}{l}\mathrm{DU}_{2}=3.39 \times \\
10^{5} \mathrm{C}-0.036\end{array}$ & & & $\begin{array}{c}\mathrm{A}=7.00 \times \\
10^{9} \mathrm{C}-1818\end{array}$ & $\begin{array}{c}\mathrm{A}=3.00 \times 10^{9} \mathrm{C} \\
-860\end{array}$ & $\begin{array}{c}\mathrm{A}=1.51 \times 10^{8} \mathrm{C} \\
-309.7\end{array}$ \\
\hline $\begin{array}{l}\text { Correlation } \\
\text { Coefficient }\end{array}$ & 0.990 & 0.999 & $0.998 *$ & $0.992 *$ & 0.996 & 0.999 & 0.997 \\
\hline $\operatorname{LOD}\left(\mathrm{mol} \mathrm{L}^{-1}\right)$ & $1 \times 10^{-7}$ & $3 \times 10^{-8}$ & $3 \times 10^{-8}$ & $1 \times 10^{-8}$ & $9 \times 10^{-8}$ & $2 \times 10^{-7}$ & $3 \times 10^{-6}$ \\
\hline LOQ $\left(\mathrm{mol} \mathrm{L}^{-1}\right)$ & $4 \times 10^{-7}$ & $1 \times 10^{-7}$ & $9 \times 10^{-8}$ & $4 \times 10^{-8}$ & $9 \times 10^{-7}$ & $2 \times 10^{-6}$ & $5 \times 10^{-6}$ \\
\hline Recovery (\%)** & $97 \pm 1$ & $99 \pm 1$ & $106 \pm 1$ & $91 \pm 1$ & $99 \pm 1$ & $96 \pm 1$ & $94 \pm 6$ \\
\hline
\end{tabular}

*Validation $\mathrm{R}$ value corresponding to $2 \mathrm{PC}$

**Values from 3 independent real samples spiked with different concentration of DCF and ATZ

\subsection{PLS Multivariate Calibration}

The PLS model showed good correlations between theoretical and predicted concentration values without outliers for both, cross and external validation. The optimal numbers of principal components (PCs) were estimated considering cross validation based criteria (Table 2). Two PCs for both ATZ and DCF were chosen. These numbers include lower values of SEV with an external validation correlation value (rVal) over 0.99 . The lowest number of PC was selected in order to not over fit the models. The regression vector (Figure 4) shows the most important wavelengths for ATZ determination are $215 \mathrm{~nm}, 230 \mathrm{~nm}$ and for DCF $195 \mathrm{~nm}$, and $205 \mathrm{~nm}, 228 \mathrm{~nm}$.
It is highlighted that the $230 \mathrm{~nm}$ maximum for regression vector is in agree with $\lambda_{\max }$ for ATZ and $198 \mathrm{~nm}$ maximum for regression vector is in agree with $\lambda_{\text {max }}$ for DCF. The $224 \mathrm{~nm}$ value for DCF quantification by SDS method agree with a shoulder of the regression vector for this compound (Figure 4). Beside this the $231.6 \mathrm{~nm}$ value, used for ATZ quantification by SDS agrees with a maximum area in the regression vector. These coincidences are evidence of the coherence of the different spectroscopic approach. The analytical parameters for the spectroscopic and chromatographic methods are showed in Table 1. It is remarkable that the values reached for the spectroscopic methods are similar to HPLC and GC-MS reference methods.

Table 2. Cross validation parameters for PLS.

\begin{tabular}{|c|c|c|c|c|c|c|}
\hline \multirow{2}{*}{ PC } & \multicolumn{3}{|c|}{ DCF } & \multicolumn{3}{c|}{ ATZ } \\
\cline { 2 - 7 } & $\begin{array}{c}\text { Variance } \\
(\%)\end{array}$ & SEV & $r_{\text {Val }}$ & Variance (\%) & SEV & $\mathrm{r}_{\text {Val }}$ \\
\hline 1 & $3.28 \times 10^{-3}$ & $1.10 \times 10^{-6}$ & 0.882 & $5.60 \times 10^{-3}$ & $6.13 \times 10^{-7}$ & 0.965 \\
\hline $2 *$ & $4.75 \times 10^{-3}$ & $1.52 \times 10^{-7}$ & 0.998 & $2.42 \times 10^{-3}$ & $3.00 \times 10^{-7}$ & 0.992 \\
\hline 3 & $4.50 \times 10^{-5}$ & $1.48 \times 10^{-7}$ & 0.998 & $5.89 \times 10^{-5}$ & $2.90 \times 10^{-7}$ & 0.992 \\
\hline 4 & $5.00 \times 10^{-5}$ & $1.49 \times 10^{-7}$ & 0.998 & $4.34 \times 10^{-5}$ & $3.03 \times 10^{-7}$ & 0.991 \\
\hline
\end{tabular}

*optimal number of PC 


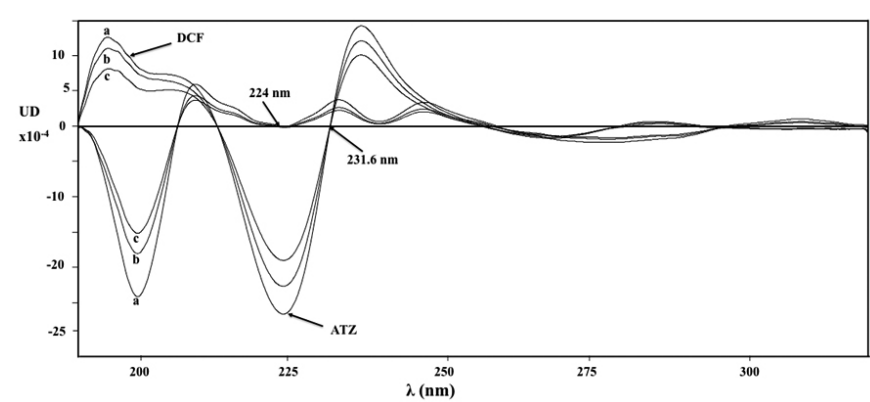

Figure 3. Second derivative spectra of DCF and ATZ measured in methanol. $\left(\mathrm{a}=2.0 \times 10^{-5} \mathrm{~mol} \mathrm{~L}^{-1}, \mathrm{~b}=3.0 \times 10^{-5} \mathrm{~mol} \mathrm{~L}^{-1}\right.$ and $\left.\mathrm{c}=4.0 \times 10^{-5} \mathrm{~mol} \mathrm{~L}^{-1}\right)$.

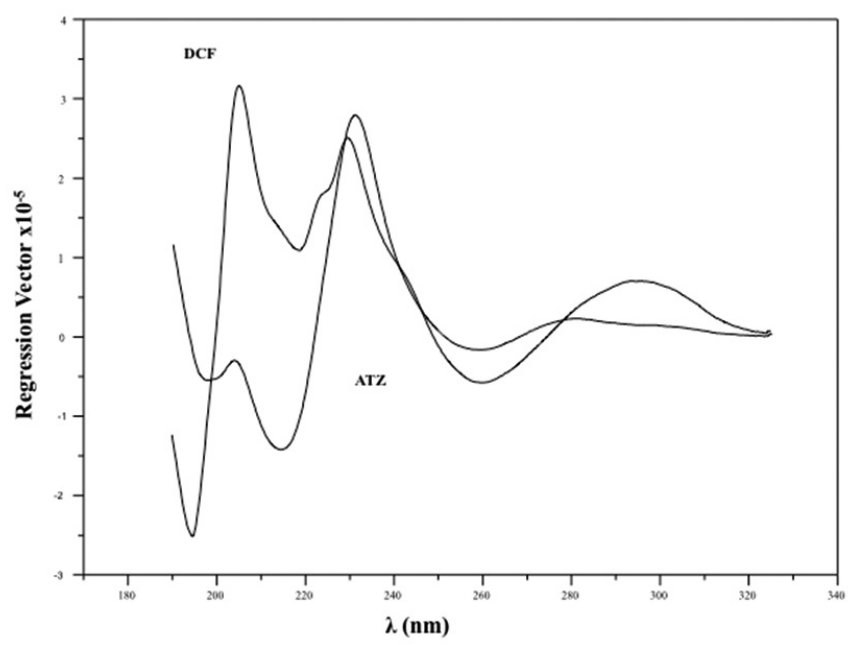

Figure 4. Regression vector for PLS model.

\subsection{Determination of $A T Z$ and $D C F$ in river water}

To determine the river water background ATZ and DCL concentrations, 5 $\mathrm{L}$ of the collected river water was pre-concentrated through a $\mathrm{C} 18$ solid phase cartridge (Oasis HLB 6cc) and eluted with $5 \mathrm{~mL}$ of methanol. After analyzing trough all analytical techniques used in this study, the results showed that ATZ or DCF was not detected in the river water. In order to determine the effect of the matrix in DCF and ATZ quantification, the water from the Bio-Bio River was spiked with known concentrations of both compounds of interest (3.0, 5.0 and 8.0$) \times 10^{-6} \mathrm{~mol} \mathrm{~L}^{-1}$. The mean recovery for these results is showed in Table 1. Comparison of expected and observed concentrations showed better values for SDS than PLS model. But both spectroscopic methods showed comparable values with the chromatographic reference methods.

\section{CONCLUSION}

The proposed methods for simultaneous determination of ATZ and DCF showed to be rapid, easy and low cost, than the quantification by HPLC, with the advantage that the LOD and LOQ were lower for the development methods.

No significative difference was found between the expected and determined concentration in samples prepared in nanopure water and in water from BioBio River. Indicative that no apparent interference of the river aqueous organic material, filtration with a $0.45 \mu \mathrm{m}$ filter (PVDF membrane) could remove most of the possible interferences.

\section{ACKNOWLEDGEMENTS}

The authors are grateful to the project FONDECYT 1110606, for the financial support.

\section{REFERENCES}

1.- J. B. Sass and A. Colangelo, Int. J. Occup. Environ. Health, 12, 260 (2006).
2.- Minnesota Department of Health, "Human Health Assessment: Atrazine", St. Paul, MN (2009).

3.- United States Environmental Protection Agency (EPA). "Restricted Use Products (RUP) Report", Registration number 524-485 (2013).

4.- H.R. Buser, T. Poiger and M.D. Müller, Environ. Sci. Technol., 32, 3449 (1998).

5.-[ J. Gröning, C. Held, C. Garten, U. Claussnitzer, S.R. Kaschabek and M. Schlömann, Chemosphere, 69, 509 (2007).

6.- $\quad$ M. Letzel, G. Metzner and T. Letzel, Environ. Int. 35, 363 (2009).

7.- R.A. Yokley and M.V. Cheung, J. Agric. Food Chem., 48, 4500 (2000).

8.- M.C. Bruzzoniti, C. Sarzanini, G. Costantino and M. Fungi, Anal. Chim. Acta, 578, 241 (2006).

9.- V. Drevenkar, G. Mendaš, S. Fingler, S. Stipievicic and L. Zupancic-Kralj, "Trace analysis of triazine compounds in water, soil and urine by gas and high performance liquid chromatography with selective detection". Institute for Medical Research and Occupational Health, Zagreb, Croatia, http://abra.fkkt.uni-lj.si/fkktstrlic/chrom02/pdf/IL/drev IL.pdf. (2002).

10.- C. Planas, A. Puig, J. Rivera and J. Caixach, J Chromatogr. A, 1131, 242 (2006).

11.- M. Schellin and P. Popp, J. Chromatogr. A, 1152, 175 (2007).

12.- M.E. Koivunen, K. Dettmer, R. Vermeulen, B. Bakke, S.J. Gee and B.D. Hammock, Anal. Chim. Acta, 572, 180 (2006).

13.- G. Gervais, S. Brosillon, A. Laplanche, and C. Helen, J. Chromatogr. A, 1202, $163(2008)$

14.- U.S. EPA's Analytical Methods Approved for Drinking Water Compliance Monitoring of Organic Contaminants. Method 525, (2009).

15.- U.S. EPA's Analytical Methods Approved for Drinking Water Compliance Monitoring of Organic Contaminants. Method 507 (2009).

16.- U.S. EPA's Analytical Methods Approved for Drinking Water Compliance Monitoring of Organic Contaminants. Method 505 (2009).

17.- J. Amador-Hernández, M. Velázquez-Manzanares, M.D. Gutiérrez-Ortiz, B. Hernández-Carlos, M. Peral-Torres, and P.L. López-de-Alba, J. Chil. Chem. Soc., 50, 461 (2005).

18.- Q.-X. Zhou and Y.-Y Gao, Chin. Chem. Lett., 25, 745 (2014).

19.- F. Qiao, K.H. Row and M. Wang, J. Chromatogr. B, 957, 84 (2014).

20.- L. Rizzo, S. Meric, D. Kassinos, M. Guida, F. Russo and V. Belgiorno, Water Res., 43, 979 (2009).

21.- D. Bendz, N.A. Paxéus, T.R. Ginn and F.J. Loge, J. Hazard. Mater., 122, 195 (2005).

22.- T. Scheytt, P. Mersmann, R. Lindstädt and T. Heberer, Chemosphere, 60, 245 (2005).

23.- P. Bartels and W. von Tümpling, Sci. Total Environment, 374, 143 (2007).

24.- J.L. Packer, J.J. Werner, D.E. Latch, K. McNeil and W.A. Arnold, Aquat. Sci., 65, 342 (2003).

25.- M. Schmitt-Jansen, P. Bartels, N. Adler and R. Altenburger, Anal Bioanal. Chem. 387, 1389 (2007).

26.- C.S. McArdel, A.C. Alder, A. Göbel, D. Löffler, M. Suter and T.A. Ternes, "Analytical Methods", in Human pharmaceuticals, Hormones \& Fragrances: The challenge of micropollutants in urban water management., ed. T.A. Ternes and A. Joss, Chap 3, IWA Publishing, London (2006).

27.- P. Perez and D. Barcelo, TrAC, Trends Anal. Chem., 26, 494 (2007).

28.- A. Demoliner, S.S. Caldas, F.P. Costa, F.F. Gonçalves, R.M. Clementin, M.R. Milani, and E.G. Primel, J. Braz. Chem. Soc., 21, 1424 (2010).

29.- I. T. I. A. C. Inc., 3.11 ed., Bothell, WA, (2003).

30.- G. Ragno, G. Ioele, and A. Risoli, Anal. Chim. Acta, 512, 173 (2004).

31.- A. Afkhami, N. Sarlak, and A. Zarei, Talanta, 71, 893 (2007).

32.- C. Soto, D. Contreras, M. Toral, L. Basáez, and J. Freer, J. Chil. Chem. Soc., 54, 113 (2009).

33.- C. Soto, D. Contreras, S. Orellana, J Yañez and M. Toral, Anal. Sci., 26, 891 (2010).

34.- A. Olivieri, N. Faber, and J. Ferre, Pure Appl. Chem., 78, 633 (2006).

35.- J. Saurina, C. Leal, R. Compano, and M. Granados, Anal. Chim. Acta, 432, 241 (2001).

36.- A. Savitzky and M. Golay, Anal. Chem., 36, 1627 (1964).

37.- ICH-Q2B Validation of Analytical Procedures, Methodology International Conference on Harmonization, (1996). 